\title{
Circular Patch FSS Micro-Strip Antenna for C Band Applications
}

\author{
Surya Deo Chaudhary, Jitendra Saroj
}

\begin{abstract}
The present paper relates to an antenna with circular patch micro-strip for the applications of $c$ band. The antenna has advantages like low profile and high selectivity, compact size, less weight. A circular type patch is chosen for the antenna over a rectangle type patch due to some advantages of circular type antenna. The size of the antenna is $60 \mathrm{~mm} \times 60 \mathrm{~mm} x$ $0.8 \mathrm{~mm}$ with an array of $3 \times 2$ size. The specification for the FR4 epoxy type substrate are: $0.8 \mathrm{~mm}$ height and 4.4 value of permittivity. The implemented antenna designing carries characteristics of dual band and the two resonating frequencies are $5.7 \mathrm{GHz}$ and $6.06 \mathrm{GHz}$ which gives significant gain. The simulation is done by using a HFFS software.
\end{abstract}

Index Terms- Micro-Strip Antenna, Gain, Frequency, FSS

\section{INTRODUCTION}

In antenna communication, size reduction is a current movement. Today amplified gain and broader bandwidth both are compulsory for present communication as explained in [1]. For satellite communication a micro-strip type antenna is the best option, however this type of antenna has low bandwidth which is the main drawback of this type of antenna. For compact size of antenna, designing slot should be kept on radiating patch which is the best idea [5]. Bandwidth enhances because, the micro-strip antenna has greater width. The patch part is designed to carry various slots wherein the region which is current concentrated is combined to unite the distributed gain. As the efficiency goes on increases with the increase in bandwidth, and hence gain decreases. Occurrence of action depends upon length of the slot and thickness of the substrate [2]. Micro-strip type antennas have a low mass, low manufacture cost, low profile, and consistent [3]. To reduce the size a defected ground type structure is taken into consideration and multiband applications. The gain is amplified and surface wave propagation gets supressed. A simpler form of micro-strip antenna is, an antenna having circular patch which modest than a micro-strip antenna having rectangular patch. 1 and 2 are the values of degree of freedom for circular and rectangular type respectively [4]. Circular type micro-strip antenna have some benefits over a rectangular type and one of those is size reduction which is $16 \%$ lesser. Other advantages are controllable radiation and easy designing.

Revised Version Manuscript Received on 10 September, 2019.

Dr. Surya DeoChaudhary, Department of Electronics \& Communication Engineering, Noida Institute of Engineering and Technology, UttarPradesh, India. (Email: researchnietip@ gmail.com)

JitendraSaroj, Department of Electronics \& Communication Engineering, Noida Institute of Engineering and Technology, UttarPradesh, India. (Email: researchnietip@gmail.com)

\section{ANTENNA DESIGN}

The designing of antenna which has been done for the experimentation, an antenna with $60 \mathrm{~mm} \times 60 \mathrm{~mm}$ having array size of $3 \times 2$. The specifications of substrate are: permittivity of the substrate is $4.4,0.8 \mathrm{~mm}$ height and it is a FR4 epoxy. It consists of an interconnected circular patch is placed above FR4 epoxy type substrate. The antenna is designed by using a 'FSS' concept. The 'FSS' is a collection of metallic patches. 'FSS' is periodic in nature, it operates in the region of radio frequency, a tinny repetitive surface. There exists various types of feeding while due to easy manufacturing a Micro-strip line feeding has been usedin the project. Same as its name, the purpose of the line is to feed. When the substrate is thicker and dielectric constant is low, then its performance is superior with bigger size of antenna Where the application is microwave based, thinner type of substrates are more appropriate. The performance of antenna is amplified by the etching slots present inside the patch of the antenna.

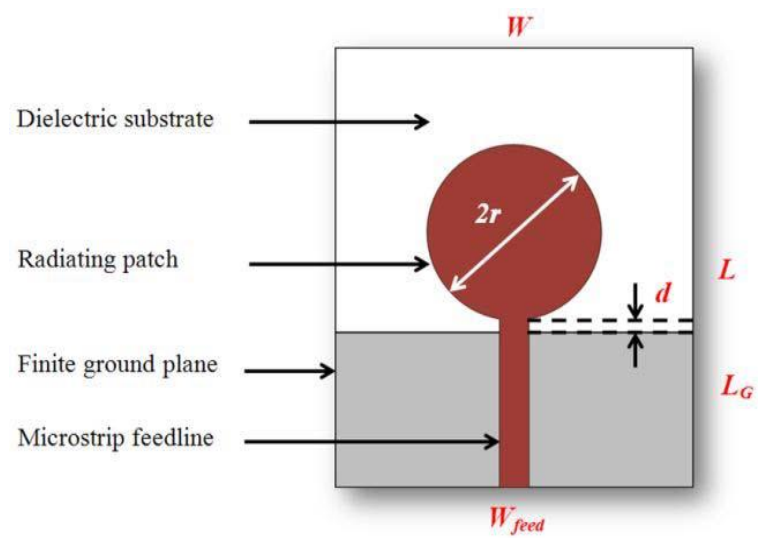

Figure 1. Circular patch and micro-strip line for feeding

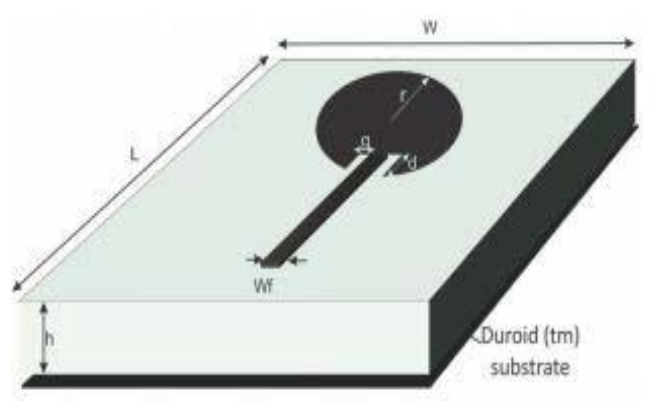

Figure 2. Circular patch and inset type feeding

Published By:

Blue Eyes Intelligence Engineering

\& Sciences Publication 


\section{CIRCULAR PATCH FSS MICRO-STRIP ANTENNA FOR C BAND APPLICATIONS}

Figure 3. Circular patch unit cell

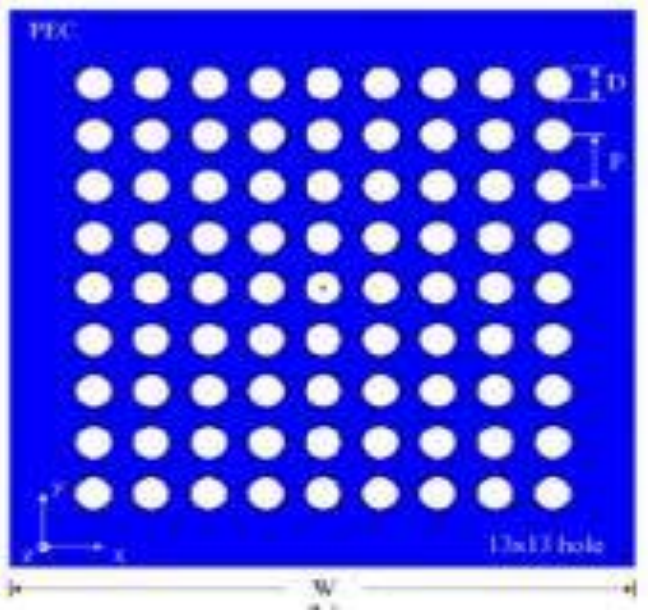

Figure 4. Circular patch and FSS array

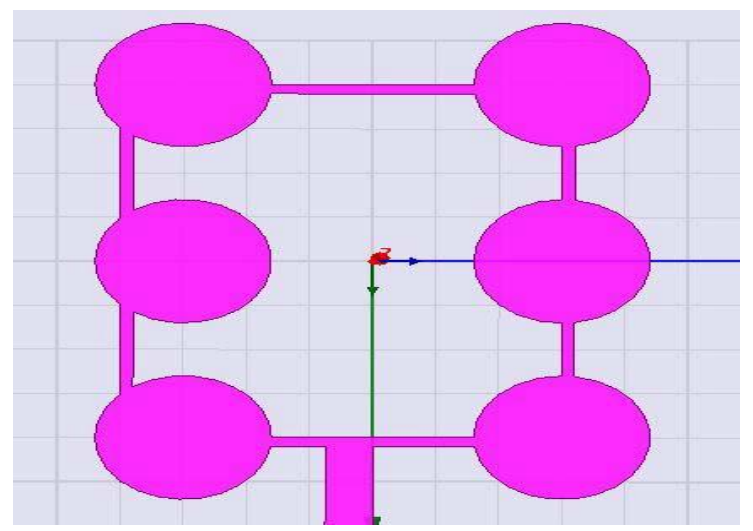

Figure 5. Proposed system design

Figure 1 illustrates a representation of circular type patch and micro-strip line for feeding.

Figure 2 represents circular patch and inset type feeding.

Figure 3 illustrates circular patch unit cell.

Figure 4 indicates circular patch FSS collection (array).

Figure 5 demonstrates the proposed design of the system.

\section{SIMULATION RESULTS AND DISCUSSIONS}

The has a size of order $60 \mathrm{~mm} \times 60 \mathrm{~mm}$ with a $3 \times 2$ array size and a height of substrate $0.8 \mathrm{~mm}$. Micro-strip line is tackled as a line of transmission. For accomplishing circular polarization, a diagonal type feeding is employed. If there is a mismatching in the load and source of generation, then total power generation is not equal to the total demand. The loss of power is called 'Return Loss' or represented by S11. When

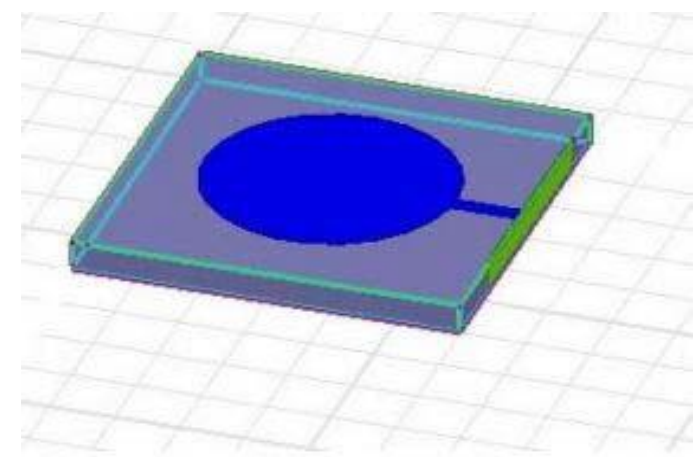

the value of this loss $\mathrm{S} 11$ is equal to $-10 \mathrm{~dB}$ means $-3 \mathrm{~dB}$ is transmitted at the load and $-7 \mathrm{~dB}$ is reflected back.

Figure 6 illustrations the scattering constraint graph. It shows dual band with the 2 resonating frequencies that are $5.7 \mathrm{GHz}$ and $6.06 \mathrm{GHz}$.

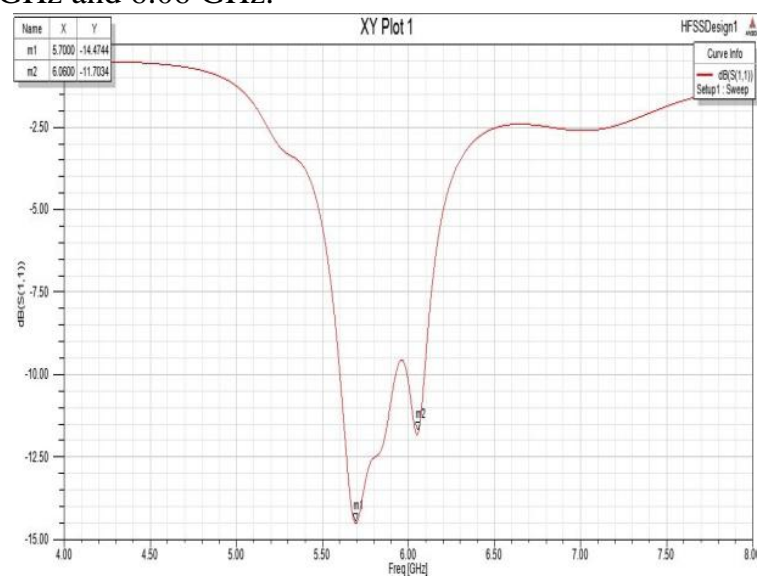

Figure 6. S11graph

In ideal case the value of VSWR is one. For matching the impedance in proper manner the value of VSWR should be below 2. If the value of VSWR upsurges then more amount of power gets reflected from the antenna and less power gets transmitted. VSWR graph is shown in Figure 7.

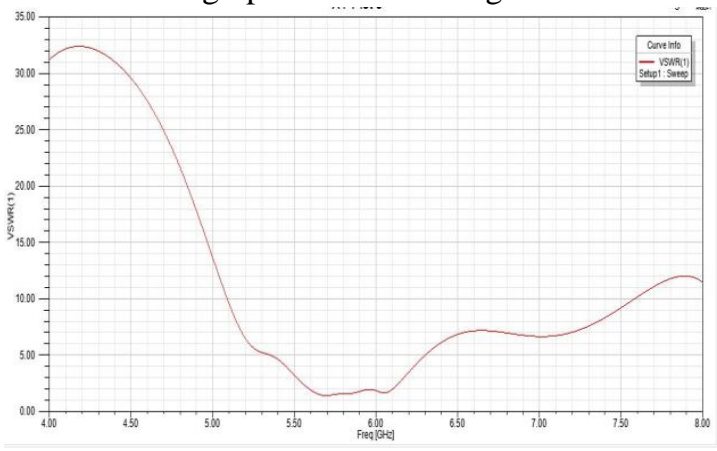

Figure 7. VSWR graph

The term 'Radiation pattern' of the antenna refers to a design that represents the track in which extreme value of power is emitted in empty space. Figure 8 and 9 represents a radiation pattern between 0 and 90 degrees at $5.7 \mathrm{GHz}$ and $6.06 \mathrm{GHz}$ frequencies respectively.

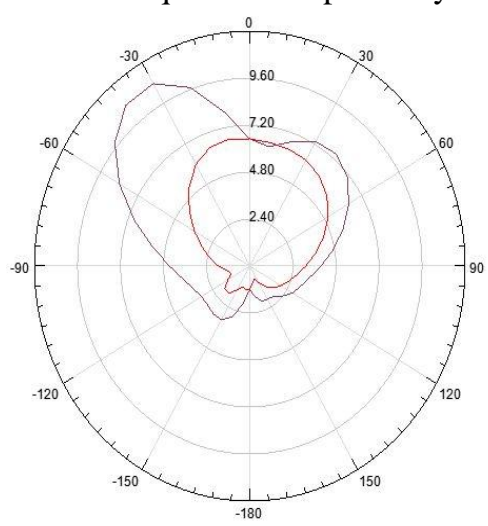

Figure 8. The radiation pattern at $5.7 \mathrm{GHz}$ between 0 and 90 degrees 

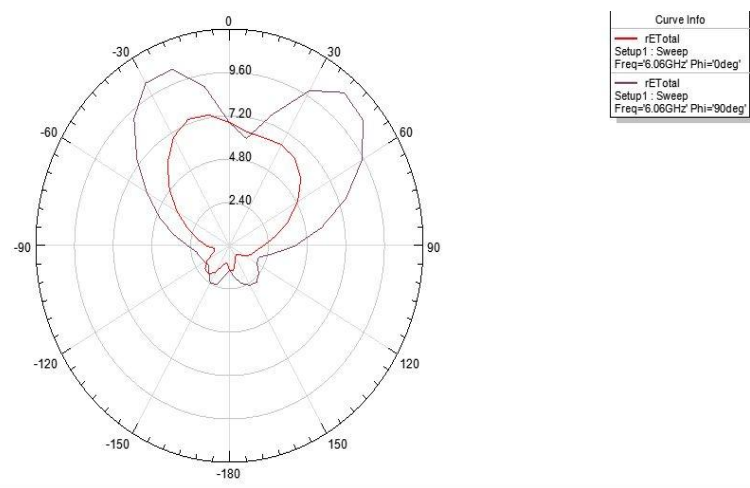

Figure 9. 0 and 90 degree radiation pattern at 6.06 GHz

To know about the conversion of input power in radio waves, there is a need to calculate the value of gain of an antenna. The directivity of antenna and electrical efficiency of antenna are interrelated by the gain.

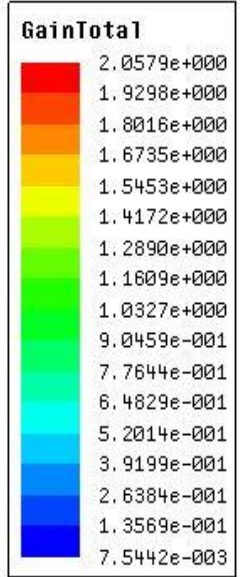

Figure 10. 3D polar plot of gain at $5.7 \mathrm{GHz}$
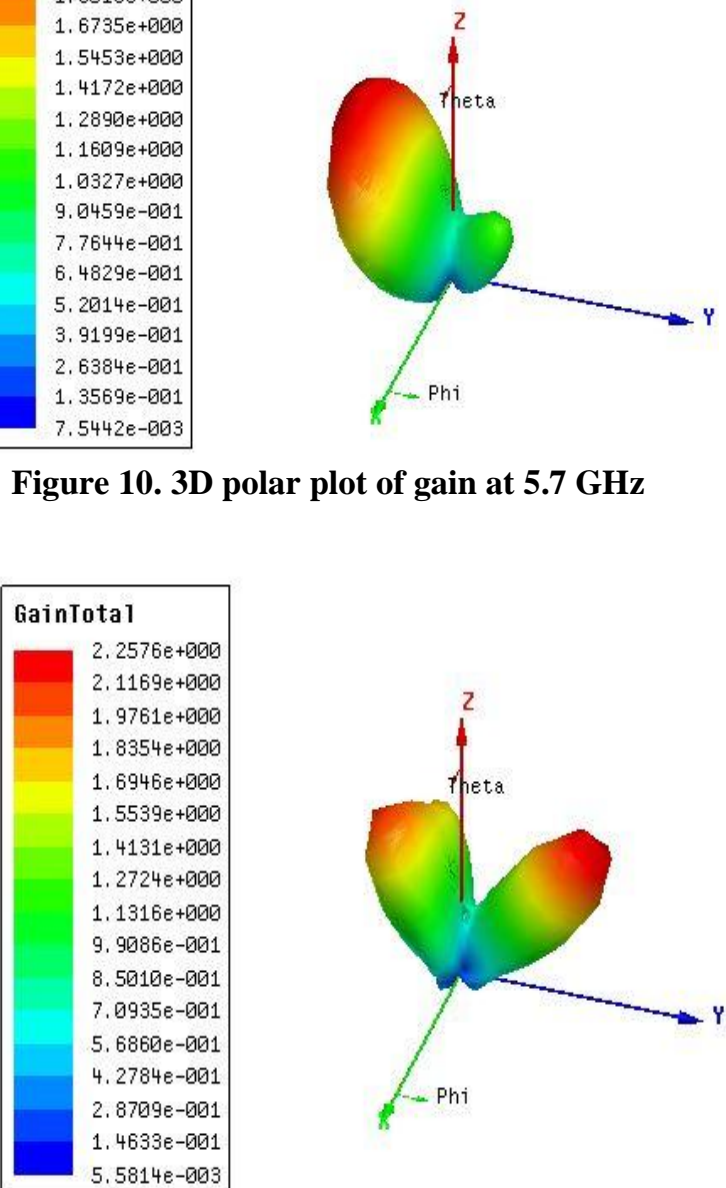

Figure 11. 3D polar plot of gain at $6.06 \mathrm{GHz}$

\section{CONCLUSION}

An antenna having low profile, low mass, compact size have been designed that accomplish all the band applications. The selectivity of the antenna is extensive and employs low electric power. A preferred value of gain i.e 2.05 $\mathrm{dBI}$ is achieved at a frequency value $5.7 \mathrm{GHz}$ and gain $2.25 \mathrm{dBI}$ is attained at frequency value of $6.06 \mathrm{GHz}$. The antenna that has been designed in this project has significant value of bandwidth and value of VSWR is less than two, further it's appropriate for ' $\mathrm{C}$ ' type band applications.

\section{REFERENCES}

1. D. Sharma and T. Shanmuganantham, "Design of miniaturised FSS microstrip antenna for $\mathrm{Ku}$ band applications," in IEEE International Conference on Circuits and Systems, ICCS 2017, 2018.

2. D. Sharma and T. Shanmuganantham, "Design of miniaturized dual band antenna using FSS," in IEEE International Conference on Circuits and Systems, ICCS 2017,2018

3. D. Cure, "Reconfigurable Low Profile Antennas Using Tunable High Impedance Surfaces," ProQuest Diss. Theses, 2013.

4. P. L. Vijayvergiya and R. K. Panigrahi, "Single-layer single-patch dual band antenna for satellite applications," IET Microwaves, Antennas Propag., 2016.

5. Zheyipei Ma, "Design of Band-Stop Frequency Selective Surface Structure with Large and stable reflection Band", IEEE transaction on antenna propagation, 2014. 